\title{
UM (O) HOMEM NA (DA) MULTIDÃO: TRAÇOS DE INTERTEXTUALIDADE ENTRE UM POEMA DE RIBEIRO COUTO E O CONTO DE EDGAR ALLAN POE
}

\author{
A (THE) MAN IN (OF THE) CROWD: ASPECTS OF \\ INTERXTUALITY BETUEEN A POEM OF RIBEIRO \\ COUTO AND EDGAR ALLAN POE'S SHORT STORY
}

\author{
ThIAGO RodRIGUes Batista*
}

Francine Fernandes Ueiss RicierI"*

\begin{abstract}
Resumo: $\mathrm{O}$ artigo analisa possíveis pontos de contato entre poemas de Um homem na multidão (1926) de Rui Ribeiro Couto e o conto "O homem da multidão" (1840) de Edgar Allan Poe. A análise prioriza movimentos de aproximação e afastamento entre os textos, a partir da relação intertextual entre os dois títulos. Partimos das concepções de Gérard Genette sobre intertextualidade para pensarmos como a relação hipertextohipotexto ajuda a compreender processos de significação decorrentes do diálogo entre as obras, bem como das leituras do flâneur em Baudelaire e no conto de Poe, por Walter Benjamin, para traçarmos paralelos com o modo de apreensão do espaço urbano pelo sujeito lírico, em Ribeiro Couto.
\end{abstract}

Palavras-chave: Ribeiro Couto, Edgar Allan Poe, poesia, flâneur, intertextualidade

Abstract: The article analyzes possible common features between poems from the book Um homem na multidão (1926) by Ribeiro Couto and Edgar Allan Poe's "The man from the crowd" (1840). The analysis focuses movements of approach and distance between the texts, emphasizing the intertextual relationship between the two titles. Considering Genette's conceptions of intertextuality, we discuss how the hypertext-hypotext relationship helps to understand the processes of signification arising from the dialogue between those works. Walter Benjamin studies about the "flâneur" in Baudelaire and in the short story of Poe are also considered as we try to stablish a parallel between those writers and the mode of apprehension of the urban space by the lyrical subject, in Ribeiro Couto.

Keywords: Ribeiro Couto, Edgar Allan Poe, poetry, flâneur, intertextuality

\footnotetext{
* Mestrando no Programa de Pós-Graduação da área de Estudos Literários da Escola de Filosofia, Letras e Ciências Humanas da Universidade Federal de São Paulo (EFLCH/Unifesp).

${ }^{* *}$ Professora de Literatura Brasileira na UNIFESP.
} 


\section{ntrodução}

O título Um homem na multidão (1926), de livro de Rui Ribeiro Couto, contém uma referência ao célebre conto "O homem da multidão" (1840), ${ }^{1}$ do norte-americano Edgar Allan Poe. Com uma sutil porém significativa alteração paratextual, o diálogo sugerido pela obra dos anos 1920 parece ensaiar tanto um movimento de aproximação quanto de distanciamento em relação ao conto. Para explorar elementos que entram em jogo nessa referência, recorremos a uma análise do poema "O vagabundo", cujas imagens se assemelham à imagética do conto, buscando esboçar as primeiras linhas de diálogo entre as obras.

No poema analisado, como em boa parte daqueles que compõem a obra, figuram observações visuais e psíquicas de um sujeito que passeia em um cenário urbano moderno, tal como no conto do escritor norte-americano. Contudo, o modo pelo qual a cidade é apreendida parece seguir um ritmo bastante diverso do ritmo sugerido na obra de Poe, que tem como cenário uma Londres cujas ruas estão permanentemente cheias de uma multidão confusa e ostensiva, com uma grande diversidade de tipos humanos. No poema de Ribeiro Couto, vemos traços de uma multidão similar, porém temos a impressão de que um filtro se coloca entre o observador e o painel humano e urbano em movimento: a paisagem urbana é de algum modo reconfigurada a partir da subjetividade do observador que, então, dá a ela um ritmo particular. Esse filtro, que nos livros anteriores do poeta surge recorrentemente em imagens de chuva, garoa e neblina, aqui parece se constituir a partir de outros recursos da linguagem poética, como examinamos na sequência.

A apreensão particular do espaço urbano pelo sujeito lírico parece tensionar-se pelas possibilidades interpretativas derivadas do rearranjo operado sobre o título do conto. Os dois elementos parecem se complementar no processo de significação que surge da referência de uma a outra obra. Compreendendo esse diálogo como uma relação intertextual nos termos propostos por Gérard Genette (2006), o artigo procura analisar de que modo a apreensão particular da cida-

\footnotetext{
${ }^{1}$ Um homem na multidão, de Rui Ribeiro Couto, foi lançado pela editora Cia e Pongetti (1926) e foi reeditado em 1960 pela José Olympio, integrando as Poesias Completas de Ribeiro Couto (volume aqui utilizado). Utilizaremos a edição de "O homem da multidão" das Histórias extraordinárias, (Companhia das Letras, tradução de José Paulo Paes, 2008).
} 
de em Ribeiro Couto se deixa complexificar, entre outros fatores, pelo processo de transformação de um texto A (o conto) por um texto B (o livro de poemas).

\section{Do diálogo paratextual à transformação no hipertexto}

Genette compreende a intertextualidade como um fenômeno menor dentro de um processo mais amplo, que denomina transtextualidade: "tudo que o coloca [o texto] em relação manifesta ou secreta com outros textos" (2006, p. 7). O autor estabelece uma tipologia dos modos de ocorrência deste processo, indo de relações textuais mais literais ou explícitas para as menos literais ou implícitas. Assim, teríamos cinco tipos de transtextualidade: i) a própria intertextualidade: relação de copresença entre dois ou mais textos; ii) a paratextualidade: relação entre o texto e o paratexto, ou seja, entre o texto e elementos exteriores a ele, como título, subtítulo, prefácio, etc; iii) a metatextualidade: relação entre um texto e o texto do qual ele fala; iv) a hipertextualidade e v) a arquitextualidade: relações entre textos que determinam suas características enquanto gênero.

A hipertextualidade, definida depois da explicitação das demais relações transtextuais, é o objeto de que o autor se ocupa diretamente em seu ensaio. Ela diz respeito à relação geral que um texto "de segunda mão" estabelece com um texto "de origem". O texto de segunda mão, ou o hipertexto, constitui-se como uma espécie de palimpsesto, pergaminho antigo constantemente apagado por copistas para que sobre ele fossem inseridas novas inscrições sem que as antigas marcas desaparecessem por completo. Genette aproxima, já na epígrafe de seu ensaio, a imagem desse manuscrito e a ideia de hipertexto: "Assim, no sentido figurado, entenderemos por palimpsestos (mais literalmente hipertextos), todas as obras derivadas de uma obra anterior, por transformação ou por imitação". (GENETTE, 2006).

A hipertextualidade é definida, então, como toda relação que une um texto $B$ (o hipertexto) a um texto A (o hipotexto), do qual o primeiro deriva. Essa derivação pode ocorrer por meio da imitação ou por meio da transformação de $A$ por B. Genette compreende que para que um texto B se transforme um texto A, basta uma modificação de qualquer em um de seus componentes. Desse modo, mudanças mínimas como a supressão ou substituição de uma letra por outra num título de uma obra, ou mesmo, em algum trecho de um enunciado, seriam 
já suficientes para a produção de um novo sentido. Esse tipo de derivação de um texto $A$ em um texto $B$, pode ser ainda mais criteriosamente denominado "transformação simples", diferenciando-se da "transformação indireta", que caracterizaria os textos que dialogam entre si através de uma relação ou um processo mimético.

Dos cinco tipos de relações transtextuais apresentados, será priorizada aqui a ideia de paratextualidade, uma vez que a análise parte da observação de um elemento paratextual. Genette a definirá como "a relação, geralmente menos explícita e mais distante, que, no conjunto formado por uma obra literária, o texto propriamente dito mantém com o que se pode nomear simplesmente seu paratexto: título, subtítulo, intertítulos, prefácios" (2006, p. 9). O autor evoca exemplos para indicar que a relação entre elementos do paratexto pode ativar significativos processos de produção de sentido que ajudam a estabelecer uma leitura das transformações que determinado hipertexto pode apresentar em relação a seu hipotexto.

A propósito dos textos em análise, podemos começar pela delimitação de traços gerais apresentados pelo problema da derivação que ocorre no paratexto. A análise parte dos possíveis processos de significação (transformação, segundo Genette) presentes na sutil alteração do título "O homem da multidão" (The man of the crowd), ${ }^{2}$ de Edgar Allan Poe para "Um homem na multidão" (A man in the crowd), de Ribeiro Couto. Essa derivação simples pode apresentar alguns caminhos iniciais para a análise.

O que parece explicitado nessa derivação são duas trocas, no caso da análise do título segundo: a do artigo definido "o" pelo indefinido "um" e a da contração prepositiva "da" por "na". No primeiro caso (da opção pelo artigo indefinido), podemos pensar numa operação que, se por um lado parece generalizar a identidade "deste homem" (um entre os demais) conferindo-lhe caráter categórico, por outro parece buscar a sua individualização pela redução a uma unidade numérica mínima: um homem em conjunto mais amplo. No conto de Poe, o artigo definido refere-se a um personagem específico, que será particularizado ao

\footnotetext{
${ }^{2}$ Como apontam Viviana Carreira (2009) e Denise Bottman (2010), as traduções de "The man of the crowd" apresentaram variações tanto no que diz respeito às preposições "da" e "na", quanto no que se refere à pluralização do termo "crowd" (O homem das multidões). Preferimos a versão "O homem da multidão", por entendermos que preserva mais literalmente o original em inglês.
} 
longo de todo o processo narrativo, em especial pelo modo como o narrador vai persegui-lo incansavelmente ao longo das ruas de Londres. Só ao final do conto a particularização parece desdobrar-se em uma espécie de impossibilidade de definição total do ser em observação, o que pode sugerir a assimilação do personagem a um típico homem da multidão. No que diz respeito aos termos que acompanham o substantivo homem, o título do conto parece ser associável, ainda, a uma relação de pertencimento desse sujeito à multidão, enquanto o título de Ribeiro Couto parece remeter a uma inserção, não se sabe se transitória, na multidão. Temos então, no caso de Poe, um tipo específico de homem que pertence à multidão, no caso de Ribeiro Couto, um exemplar qualquer de homem, que está na multidão.

\section{Entre o homem da multidão e a figura do flâneur}

Em linhas gerais, o conto de Poe acompanha o ponto de vista de um narrador que observa, por uma grande janela dentro de um café, os movimentos de uma multidão que passa, no fim de uma tarde de outono, pelas ruas movimentadas da Londres de meados do século XIX. Esse narrador busca adivinhar, pelas vestimentas e trejeitos das pessoas, as profissões, as ambições, as histórias de vida que acabam por identificá-las a tipos comuns e aos estratos sociais a que pertencem. Nesse exercício, vai distinguindo fidalgos, comerciantes, negociantes, agiotas, baixos e altos funcionários, batedores de carteira, jogadores, militares, enfim, todos os tipos que compõem a massa de transeuntes. Conforme a noite avança, o interesse pela multidão aumenta por ser o momento em que ela passa a ficar mais caótica e grosseira.

Ocorre, então, uma mudança na ação pelo surgimento na multidão de um homem misterioso, descrito como um velho decrépito cujo semblante e a "absoluta idiossincrasia da expressão" causam fascínio no narrador que nunca vira algo parecido e se vê impedido de decifrar, como fazia até então, a que estrato social ou a que tipo de história tal homem estaria ligado.

A partir desse momento, o narrador passa a perseguir, em meio à multidão, o homem misterioso que lhe desperta curiosidade e fascínio. Após uma longa jornada que terminará na manhã do dia seguinte, percebe-se que o homem não tem qualquer destino claro. Ele vaga de maneira imprevisível pelas ruas, entra 
em lojas sem objetivo algum, se afasta e retorna para a multidão, se detém por alguns segundos, absorto em seus pensamentos, para logo em seguida voltar a agir aleatoriamente. Sem conseguir entrever, então, nada de sua motivação ou de qualquer objetivo que permita compreender os movimentos desse homem, o narrador decide por abandonar sua investida. Nesse momento, ele conclui ser esse velho o próprio "homem da multidão", "o tipo e o gênio do crime profundo", que se recusa a estar só, concluindo ainda que nada poderá saber a respeito dele ou de seus atos, sendo inútil continuar a segui-lo.

Este "tipo e gênio do crime profundo" que tanto espanto causa ao narrador de Poe guarda, para Walter Benjamin (1994), alguns aspectos de proximidade com a figura do flâneur, figura típica do cotidiano urbano parisiense de meados do século XIX e espécie de burguês que, tendo o tempo à sua disposição, o desperdiça observando a multidão que compõe a paisagem da Paris oitocentista. Para Benjamin, este tipo representa no conto de Poe antes de tudo, alguém incapaz de se sentir seguro na sociedade, sendo este o motivo de buscar na multidão seu abrigo. Nela, a melhor guarida seria a possibilidade do anonimato. Nesse sentido, o conto de Poe, para Benjamin, pode ser compreendido como uma espécie de radiografia do romance policial. Embora sem a presença do crime, nele estariam associados o potencial do proveito do anonimato e a possibilidade do afloramento do que há de desconhecido no comportamento humano, sob o abrigo da multidão:

Para Poe, o flâneur é acima de tudo alguém que não se sente seguro em sua própria sociedade. Por isso busca a multidão; e não é preciso ir muito longe para achar a razão por que se esconde nela. A diferença entre o anti-social e o flâneur é deliberadamente apagada em Poe. Um homem se torna tanto mais suspeito na massa quanto mais difícil é encontrá-lo. Renunciando a uma perseguição mais longa, o narrador assim resume em silêncio sua compreensão: “- Esse velho é a encarnação, o gênio do crime - disse a mim mesmo por fim - Ele não pode estar só; ele é o homem da multidão". (BENJAMIN, 1994, p. 45)

Para Roberto Massagli (2008), em leitura comparativa entre o homem da multidão de Poe e o flâneur de Baudelaire, as características deste na obra do poeta francês, mesmo que guardando semelhanças com o velho caminhante do conto, dele se distanciarão na medida em que o caminhante baudelairiano dificilmente 
chega a agir como um autômato a vagar sem destino, como um ser destituído de qualquer individualidade. Como em Poe, o flâneur na obra de Baudelaire veria a cidade como um espaço sedutor e constantemente se veria "inebriado pelo prazer de se achar em uma multidão" (MASSAGLI, 2008, p. 56). Contudo, haveria aqui uma relação particular com o espaço urbano moderno que entraria em correspondência com a proposta estética baudelariana de buscar a beleza na multiplicidade e no efêmero. Nesse sentido, ele buscaria a experiência do contraditório ao integrar-se numa série de experiências antitéticas, em que toma contato com a "unidade na multiplicidade", com a "tensão na indiferença", com o "sentir-se sozinho em meio aos seus semelhantes" (2008, p. 56). Ainda segundo Massagli, a rua surgiria como refúgio e se, por um lado, nela ele buscaria a identificação com a sociedade, por outro, constataria que o homem moderno está vitimado pelo domínio das mercadorias, anulado na multidão e condenado a vagar pela cidade em estado de abandono.

Sua diferença em relação ao autômato representado na figura do velho decrépito do conto de Poe e em relação aos indivíduos anulados na massa da multidão urbana, entre outros aspectos, consistiria em sua condição de "figura de um burguês que tem o tempo a sua disposição e que pode dar-se ao luxo de desperdiçá-lo" (2008, p. 57), entrando em choque, inclusive, com a dinâmica utilitarista da cidade. Além disso, ele se distingue pela natureza de seus interesses, fundamentalmente estéticos, que o tornam um leitor da cidade que, se por um lado, não observa a multidão de fora, sendo antes um partícipe dela, por outro, o faz como um observador distraído em busca de uma apreensão "fragmentária e momentânea" do cotidiano.

Walter Benjamin impressiona-se com o modo como a multidão é apresentada por Poe; para ele, o fascínio com que o narrador a descreve faz dela mesma, pela notação de seus movimentos e dos tipos que a compõem, um interesse quase que autossuficiente na narrativa, na medida em que é observada como espetáculo. Um aspecto importante dessa descrição estaria no jogo entre variedade de tipos e uniformidade de comportamento que as pessoas adquirem quando no meio da multidão, agindo quase automaticamente, ainda que absortas em seus próprios interesses:

Seu traço magistral nessa descrição consiste em expressar o isolamento desesperado dos seres humanos em seus interesses privados, não como o fez Senefelder - 
através da variedade de sua conduta -, mas sim na absurda uniformidade de suas roupas ou comportamento. (BENJAMIN, 1994, p. 50)

Benjamin nota ainda outro traço importante no modo como a multidão é descrita no conto e isso estará relacionado com a passagem do tempo. Levando a ação para um cenário notívago, em que a escuridão da noite se mistura à luz difusa dos lampiões a gás, a paisagem urbana e a massa de pessoas são saturadas de um inquietante tom de mistério:

Conforme a noite avançava, progredia meu interesse pela cena. Não apenas o caráter geral da multidão se alterava materialmente (seus aspectos mais gentis desapareciam com a retirada da porção mais ordeira da turba, e seus aspectos mais grosseiros emergiam com maior relevo, porquanto a hora tardia arrancava de seus antros todas as espécies de infâmias), mas a luz dos lampiões a gás, débil, de início, na sua luta contra o dia agonizante, tinha por fim conquistado ascendência, pondo nas coisas um lustro trêmulo e vistoso. (POE, 1840/2008, p. 262)

A respeito dos efeitos dessa luz sobre a multidão, Benjamin abordará ainda um processo que caracterizaria o espaço urbano no século XIX, a partir da iluminação pública das grandes cidades, desde a distribuição de lampiões a gás pelas ruas até a iluminação a energia elétrica. Isso teria removido do cenário cotidiano a imagem do céu estrelado, numa mudança que mais tarde se radicalizaria com a proliferação de prédios altos. Em decorrência, a lua ou as estrelas já não seriam dignas de menção, já não comporiam a paisagem da cidade moderna. $\mathrm{Na}$ Paris do século XIX, isso caracterizaria a grande época do noctambulismo. Como veremos adiante, a apreensão do espaço urbano pelo sujeito do poema "O vagabundo" terá relação com a figuração da lua em meio à paisagem observada, parecendo funcionar como índice de uma postura de desconfiança em relação a certa ideia de progresso oculta sob a dinâmica da cidade. 


\section{Um homem desconfiado na multidão}

De maneira geral, a obra de Ribeiro Couto traz constantemente a figura de um observador que poderia ser aproximado à figura do flâneur. Vera Lins (1997), ao se deter sobre alguns traços do sujeito lírico presente nas obras iniciais do autor, aponta para certa predileção pelos ambientes noturnos e para a presença de um olhar que busca apreender, de maneira vaga e imaginativa, as paisagens urbanas. Estes traços, tal como ocorrem em poemas de Ribeiro Couto, indicariam, para Lins, uma remissão direta aos poemas de Baudelaire, bem como a certa poesia penumbrista, para a qual essa figura seria um elemento recorrente. ${ }^{3}$

Podemos pensar, portanto, que o diálogo entre Um homem na multidão e o conto de Poe parece ter na figura do flâneur também um elemento central. Assim como ocorre em Baudelaire, a relação entre essa figura e o homem da multidão, se por um lado encontra semelhanças no que diz respeito à sedução da multidão e à necessidade de estar inserido nela, por outro, dele se distancia na recusa ou na tentativa de resistir à condição de automatização a que o velho se vê sujeito, já impossibilitado de se distanciar minimante da turba, numa espécie de pertencimento acrítico e alienado.

Para Benjamin, um primeiro aspecto importante para compreender as tensões com que o flâneur baudelairiano apreende o espaço urbano a sua volta, se dá em comparação com o modo como isso se dava nas fisiologias. Espécie de foIhetim e um dos primeiros gêneros literários a tematizar a vida urbana moderna, as fisiologias tratariam o tema atenuando aspectos negativos do choque a que os indivíduos constantemente são submetidos no espaço urbano. O observador (também um flâneur) do painel apresentado aí, semelhantemente a Baudelaire, transforma as ruas e as galeries parisienses numa espécie de moradia.

As fisiologias apresentariam, contudo, um panorama atenuado da vida urbana, em que a visão do outro se distanciaria da experiência e das circunstâncias novas e inquietantes que caracterizariam a vida nas grandes cidades. Para Benjamin, "o mais indicado [nesse tipo de texto] seria dar às pessoas uma imagem amistosa das outras. Com isso, as fisiologias teciam, a seu modo, a fantasmagoria da vida parisiense" (1994, p. 36). Nesse gênero, mesmo a imagem do observador capaz de distinguir os tipos na variedade da multidão operaria como um

\footnotetext{
${ }^{3}$ Sobre penumbrismo ou crepuscularismo em Ribeiro Couto, consultar Norma Goldstein (1983).
} 
recurso retórico capaz de diluir a inquietante sensação de se estar em meio a desconhecidos, ou entre potenciais suspeitos acobertados na massa.

Assim como Poe, pensa Benjamin, Baudelaire se afastará de uma figuração amena do urbano, procurando compô-lo também a partir dos aspectos inquietantes da vida na cidade. Tal como em Poe, em Baudelaire também estariam presentes, embora de maneira dispersa, elementos do romance policial, especialmente no que se refere à imagem da multidão e da noite como propiciadoras da possibilidade do crime e do afloramento do que há de temível no comportamento humano. Benjamin vê no poema "O crepúsculo vespertino", de As flores do mal, um exemplo disso:

Eis a noite sutil, amiga do assassino;

Ela vem como um cúmplice, a passo lupino;

Qual grande alcova o céu se fecha lentamente,

E em besta fera torna-se o homem impaciente.

[...]

Pela cidade imunda e hostil se movimenta

Como um verme que o Homem furta o que o sustenta. (BAUDELAIRE, 2012, p. 335)

Há, todavia, na apreensão do espaço urbano pelo flâneur baudelairiano, também elementos que apontariam mais a figuração do desejo de experienciá-la esteticamente, por meio da tentativa de apreensão do belo no efêmero. Por meio desse interesse - aspecto importante da visão estética de Baudelaire - o observador tiraria proveito das condições propiciadas pela cidade em prol do prazer particular de se tornar um "caleidoscópio dotado de consciência, que, a cada um de seus movimentos, representa a vida múltipla e o encanto cambiante de todos os elementos da vida" (BAUDELAIRE, 2006, p. 857). O anonimato propiciado pela massa, neste caso, dá ao flâneur ideal de Baudelaire a possibilidade de "desposar a multidão", agindo conscientemente sobre ela. Este agir o caracterizaria, então, como um "eu insaciável do não eu, que a cada instante o revela e o exprime em imagens mais vivas do que a própria vida, sempre instável e fugidia" (2006, p. 857).

Ainda que dinâmica, instável e fugidia, a figuração desse eu parece ainda resguardar a individualidade do sujeito diante da multidão. Nesse sentido, o flâneur em Baudelaire se afastará significativamente do homem da multidão de 
Poe, que vaga sem qualquer interesse aparente e que parece desumanizado e destituído de consciência. Neste aspecto, o flâneur de Ribeiro Couto estará mais próximo do observador baudelairiano, na medida em que, a despeito de seu desejo de proximidade com a multidão, ainda será capaz de se distanciar dela e de possuir certa autonomia que lhe possibilita observá-la em suas contradições, além de levar a cabo um outro desejo, o de experienciá-la esteticamente.

Isso parece ficar claro no poema "O vagabundo", que descreve uma cena urbana sob o ponto de vista de um sujeito que se aproxima, desde o título, da figura do flâneur, pelo caminhar avesso ao da sociedade burguesa, por não se identificar a partir de uma profissão. O poema tem caráter descritivo e apresenta um fragmento de vida urbana, ainda que composto por uma série de outros fragmentos de imagens do cenário da cidade. À primeira vista, não há nenhuma indicação direta a alguma reação subjetiva desse sujeito em relação ao que vê, o que sugere uma completa inserção desse homem no espaço que o circunda:

\section{0 vagabundo}

Sugestões do escurecer nas ruas barulhentas,

Quando, pelas calçadas, a multidão vai à pressa,

Quando os automóveis passam à disparada,

Quando um começo de lua desmaia no céu, Quando o céu é claro mas sente-se que é noite, Quando uma pequena luz se acendeu ao longe...

Sugestões do escurecer vendo as montanhas ao fundo,

Vendo o mar onde as ilhas imóveis naufragam,

Vendo as mulheres passearem no cais lentamente,

Vendo velhos nos bancos, debaixo de árvores,

Vendo uma criança que passa no colo da ama...

Sugestões do escurecer ouvindo o rumor da cidade,

Ouvindo o rumor da cidade imensa,

Seu confuso rumor feito de tantos rumores,

Ouvindo o rumor da vida, o rumor do tumulto... 
Sugestões do escurecer quando das casas patriarcais, Através do silêncio dos jardins adormecidos, Vem a alegria das salas de jantar iluminadas... (COUTO, 1960, p. 113)

A primeira e a terceira estrofes do poema são as que mais possuem proximidade com a representação tumultuosa da multidão, tal como apresentada em Poe. A segunda e quarta estrofes parecem indicar uma necessidade de descrever de maneira ampla a cidade de que se fala, tanto suas regiões mais tumultuosas, quanto as mais calmas. O que se pretende apontar aqui, contudo, é a postura diante da multidão que esse observador parece estabelecer. A repetição, nos versos 1, 7, 12 e 16 do sintagma "Sugestões do escurecer" parece fornecer alguma pista da postura desse sujeito em relação àquilo que vê. É possível ver aí uma ambiguidade que sugere certa desconfiança desse observador sobre o espaço observado. No primeiro dos quatro versos, por exemplo, temos duas possibilidades de leitura, a primeira puramente descritiva, indicando apenas que a noite cai sobre as ruas barulhentas. É possível, porém uma leitura em que as "ruas barulhentas" funcionem como o elemento que sugere o escurecer, como se esse fragmento da paisagem representasse, metonimicamente, outro escurecer, um escurecer metafórico.

Tal leitura pode ser transferida para outros versos que começam como o primeiro, de modo que, tanto ver as montanhas ao fundo (assim como o mar, as mulheres no cais, os velhos nos bancos, a criança no colo da ama), ouvir o rumor da cidade (o rumor confuso de uma cidade imensa), quanto a alegria das salas de jantar das casas patriarcais, todas essas visões podem ser anunciar o surgimento dessa outra noite, que parece querer indicar algo além da simples passagem do tempo.

Outro elemento que parece indiciar essa dupla leitura seria a repetição da conjunção "quando", que sujeita todos os versos da primeira estrofe a uma mesma partícula indicativa de tempo e que remete ao momento da observação. Seria como se tal momento se dilatasse, enquanto se prolonga por cinco versos. Essa dilatação é acompanhada ainda por um movimento que vai do uso de imagens mais concretas a imagens de teor mais abstrato. Assim, nos primeiros três versos, entramos em contato com elementos tão típicos de uma paisagem urbana moderna quanto o podem ser ruas barulhentas, uma multidão que vai 
apressada pelas calçadas e automóveis passando em disparada. Logo em seguida, porém, quase que por uma justaposição de imagens, somos levados a mudar completamente o foco do olhar para o céu noturno.

Na segunda estrofe do poema, assim como ocorre com a conjunção "quando", a repetição do verbo "vendo" também sugere o efeito de prolongamento, no caso, do ato de ver. A escolha da forma verbal no gerúndio potencializa esse efeito, enquanto denota uma ação em acontecimento. Aqui, então, como na estrofe anterior, este observador também se transporta para outro tempo, que se afasta de uma temporalidade de referencial realista. 0 movimento das imagens também é outro, partindo de um verso metafórico ("vendo o mar onde as ilhas imóveis naufragam") para chegar à imagem de "uma criança que passa no colo da ama...". Nesta estrofe, as imagens são menos cinéticas do que as da estrofe anterior; a movimentação é claramente mais lenta, em parte porque se distancia do referencial de desordem urbana. A imagem do cais aqui se articula com elementos típicos de uma paisagem mais provinciana, onde se veem mulheres passeando lentamente, velhos sentados nos bancos debaixo de árvores, crianças sendo levadas no colo.

O segundo verso da estrofe, sendo o mais carregado de sentido pela metáfora, traz também uma ambiguidade interessante na medida em que retoma algo da estrofe anterior ao mesmo tempo em que serve como transição para o que vem a seguir. Por um lado, "o mar onde as ilhas imóveis naufragam" pode sugerir um movimento - em consonância com as descrições de Poe - de anulamento dos indivíduos (ilhas imóveis que naufragam) na multidão (o mar). Por outro, funciona também como lastro descritivo que mantém a coerência na passagem de uma estrofe para outra, que se dá por um movimento de ascensão - da rua para o céu - seguido por um movimento de queda - das montanhas para o cais. A imagem do mar, neste caso, ajuda a dar coerência à figuração do espaço, reconfigurado, então, como um porto.

A terceira estrofe, junto com o início da primeira, será talvez a que mais se aproxima da imagética do conto de Poe, ao menos na sugestão de desordem, de um movimento que ultrapassa a capacidade de apreensão completa do fenômeno da multidão ou dos tumultos. Os versos que a compõem parecem querer traduzir pela sonoridade, especialmente pela assonância gerada pela repetição da palavra "rumor", a impressão de zunido que se expande exponencialmente nas cidades. Há aqui algo de assustador diante da cidade que é imensa, há a impres- 
são da fragmentariedade da vida urbana ("seu confuso rumor feito de tantos rumores"), e uma aproximação de vida em tumulto. Cabe notar ainda que, nesta estrofe, parece ser interrompido o movimento de repetição de palavras iniciais ao longo dos versos, como ocorria anteriormente com a conjunção "quando" e com verbo "vendo". A opção será mais a de gerar um efeito sonoro concreto de confusão do que sugerir o prolongamento dos sentidos, embora isso ainda se mantenha presente pela repetição do verbo "ouvir".

A última estrofe parece, enfim, tecer um comentário irônico sobre talvez o único elemento que nessa paisagem urbana se mantém imóvel e impermeável ao rumor das ruas: a alegria das salas de jantar iluminadas das casas patriarcais. Esse tipo de casa é uma imagem que Ribeiro Couto retoma de seus livros iniciais e que remete aos palacetes de bairros elitizados, com jardins e portões à frente. Seu flâneur os descreve constantemente em O jardim das confidências (1921), tentando entrever, da rua, o que se passa no interior, tentando adivinhar de quem seria o vulto feminino que às vezes, surge atrás de suas janelas. Dialogando com isso, há um poema dedicado a São Paulo, em Um homem na multidão, em que Ribeiro Couto, ao figurar elementos da geografia urbana, parece compreender o tumulto e o silêncio como marcas de hierarquia social:

A neblina esconde um pouco o contorno das grandes fábricas ao longe,

Perdidas na planície, entre o chato casario proletário.

E tudo cor de barro novo, como se fosse manchado de sangue!

Nas ruas do centro agita-se a pressa do comércio.

Nos bairros burgueses, no entanto, há silêncio.

As alamedas adormecem sob o silêncio.

Os jardins adormecem sob o silêncio. (1960, p. 132)

Analogamente a este silêncio, a sossegada cena do jantar das casas com jardins em "O vagabundo", bem como a marca dessa hierarquia social, também sugerem o escurecer metafórico retomado ao longo do poema. Nesse sentido, a tensão criada a partir da relação entre espaço e ruído - na estrofe anterior do poema sugere-se o tumulto dos rumores da grande cidade - exemplifica o que no início do trabalho indicamos como um filtro através do qual o sujeito apreende o espaço urbano em Um homem na multidão. Aqui, a tensão e a particularização do olhar se dão a partir da aproximação de imagens contraditórias, 
mas concretas, de uma mesma cidade, contrapondo-se características de uma de suas regiões às de outras.

Se pensarmos em delimitar o exato momento da cena descrita em "O vagabundo", este seria talvez o momento do crepúsculo, recorte temporal caro à poesia de Ribeiro Couto e que parece propor uma indeterminação entre dia e noite, sendo privilegiado também no conto de Poe. É nesse momento que um sugestivo "começo de lua" desmaia num céu que, apesar de claro, já se apresenta como noite. A lua parece significar ao mesmo tempo luz e escuridão, embora penda mais para a penumbra, já que desmaia, como se estivesse se apagando dolentemente. É nesse momento, aliás, que se vê a necessidade de se acenderem luzes diante de uma claridade que vai esmorecendo. Assim que a lua desmaia, ao longe uma pequena luz se acende, numa sugestão que evoca algo dos lampiões aos poucos acesos na Londres do conto. Essa luz antinatural, contudo, está sintaticamente subordinada ao verso "Sugestões do escurecer nas ruas barulhentas", sendo também ela um índice da noite metafórica que se aproxima.

Mas, enfim, o que seria essa outra noite, este outro escurecer que se insinua desde o primeiro verso do poema? O quinto verso da primeira estrofe parece nos dar uma pista que nos permite compreender este escurecer como, talvez, uma espécie de alusão pessimista ao caráter ambíguo de uma vida urbana que, caminhando na esteira da ideia pretensamente luminosa de progresso ("o céu é claro"), é vista com desconfiança pelo observador quanto às nebulosas consequências de um futuro temerosamente desconhecido ("mas sente-se que é noite").

O poema todo, aliás, parece trabalhar sobre essa antítese entre luz e escuridão, dois elementos que parecem pairar sobre tudo o que caracteriza o espaço urbano observado. Já no primeiro verso isso se dá à medida que o escurecer é sugerido na metonímia "ruas barulhentas". Este verso parece resumir grande parte do poema: sendo uma imagem direta da cidade, em que o espaço central é a rua e sua condição o tumulto, o barulho, ela será também o prenúncio de algo desconhecido, confuso, que está por vir e que traz desconforto por ser difícil de ser compreendido. É nesse sentido que a pequena luz que se acende ao longe, no sexto verso do poema, assim como a débil iluminação a gás, em quase nada contribui para clarificar o espaço urbano e sua dinâmica, dotando-o, ao invés disso de mais mistério e penumbra. 
Essa correspondência entre luz e penumbra, claridade e obscuridade, parece inclusive evocar a imagem baudelairiana do fanal obscuro, utilizada pelo poeta como metáfora da ideia de progresso: "A ideia de progresso. Este fanal obscuro, invenção do filosofismo atual. Brevidade sem garantia da natureza ou da Divindade, esta lanterna moderna lança suas trevas sobre todos os objetos do conhecimento." (BENJAMIN, 2006, apud RAMIREZ, 2010, p. 252). Não faltam leituras dessa imagem que buscam compreender como sua obra se refere ceticamente à noção de progresso como ideologia, especialmente tal como aparece no século $X I X^{4}$. Ao contrário de uma visão otimista das melhorias advindas do progresso científico e material, o observador de Ribeiro Couto se aproxima do ceticismo de Baudelaire, já que, como o poeta francês, parece desconfiar dos aspectos sombrios desse processo:

Que coisa mais absurda o progresso, quando o homem, como o provam os fatos de cada dia, está sempre semelhante e igual ao homem, vale dizer, sempre no estado selvagem! Que representam os perigos da floresta e do campo em face dos choques e dos conflitos da civilização? (BENJAMIN, 1985, apud LINS, 1997, p. 19)

Seriam necessárias análises de mais poemas para melhor explorarmos como o diálogo com o título do conto de Poe aponta para uma transformação de imagens no livro de Ribeiro Couto. Alguns aspectos desse diálogo entre as obras, contudo, puderam vir à tona ao longo do artigo e a derivação observada no paratexto, se levarmos em consideração a postura do observador do poema aqui analisado, parece indicar, por enquanto, mais um movimento de afastamento da subjetividade lírica presente no poema em relação à imagem do velho que caminha sem rumo, no conto. Retomando o início de nossa análise, o "estar" na multidão do observador, em "O vagabundo", parece denotar uma recusa ao simples "pertencer" a ela.

A presença da figura do flâneur, que pode, inclusive, ser explorada em diálogo com outros textos, parece fundamental para essa compreensão, uma vez que aponta para uma postura que ainda guarda certa relação de independência diante do processo de alienação e constante anulação do sujeito no espaço urbano moderno. Pensando o observador presente no poema a partir da figura

\footnotetext{
${ }^{4}$ Sobre reflexões de Benjamin a respeito dessa questão em Baudelaire, ver: Ramirez (2010, p. 252).
} 
do flâneur, parece possível entrever uma leitura para o "estar" na multidão que indicaria uma relação dinâmica entre o sujeito e a turba. Ao não "pertencer" simplesmente à multidão, ele parece, mesmo estando imerso na massa coletiva, resguardar ainda para si a possibilidade de sua individualidade, na medida em que em seu modo particular de experienciar a multidão toma contato com seus pontos cegos e entrevê sua contraparte obscura.

\section{Referências}

BENJAMIN, Walter. A modernidade e os modernos. Rio de Janeiro: Tempo Brasileiro, 2000.

BENJAMIN, Walter. Obras escolhidas III: Charles Baudelaire um lírico no auge do capitalismo. São Paulo: Brasiliense, 1994.

BAUDELAIRE, Charles. As Flores do mal. Trad. e notas Ivan Junqueira. Rio de Janeiro: Nova Fronteira, 2012.

BAUDELAIRE, Charles. O pintor da vida moderna. In Poesia e prosa. Rio de Janeiro: Nova Aguilar, 2006.

BOTTMAN, Denise. Alguns aspectos da presença de Edgar Allan Poe no Brasil. Tradução em Revista, Rio de Janeiro, v. 1, n. 08, 2010.

CARREIRA, Viviane. "The man of the crowd" em português: um estudo comparativo-descritivo de três traduções do conto de Edgar Allan Poe. Cadernos de Tradução, Santa Catarina, v. 2, n. 24, 2009.

COUTO, Ribeiro. Poesias completas. Rio de Janeiro: José Olympio, 1961.

GENETTE, Gerard. Palimpsestos: a literatura de segunda mão. Extratos traduzidos por Luciene Guimarães e Maria Antônia Ramos Coutinho. Belo Horizonte: Imprensa Universitária, 2006.

GOLDSTEIN, Norma. Penumbrismo e Modernismo. São Paulo: Ática, 1983.

LINS, Vera. Ribeiro Couto, uma questão de olhar. Rio de Janeiro: Fundação Casa de Rui Barbosa, 1997.

MASSAGLI, Sérgio Roberto. Homem da multidão e o flâneur no conto "O homem da multidão", de Edgar Allan Poe. Terra roxa e outras terras, Londrina, v. 12. jun. 2008.

POE, Edgar Allan. Histórias extraordinárias. São Paulo: Cia. das Letras, 2008.

RAMIREZ, Paulo Nicolli. A Revolução Vagabunda: Baudelaire, Walter Benjamin e o fim da história. Revista ponto-e-vírgula, São Paulo, n. 8. Disponível em: $<$ http://revistas. pucsp.br/index.php/pontoevirgula/article/view/13955>. Acesso em: 4 fev. 2017. 